\title{
Dossiê Habilidades Sociais
}

\section{Adriana Benevides Soares}

Universidade do Estado do Rio de Janeiro - UERJ, Rio de Janeiro, RJ, Brasil

Em 1996 foi publicado o primeiro artigo conceitual relativo ao campo das habilidades sociais por Zilda e Almir Del Prette descortinando um novo capítulo na história da Psicologia em nosso país; a Psicologia das Habilidades Sociais. Naquele artigo os autores relatavam basicamente os marcos históricos na Europa, nos Estados Unidos e na América Latina assim como identificavam os principais conceitos do campo até hoje debatidos intensamente: o conceito de habilidade e competência social. Logo depois, em 1999, o primeiro livro e o primeiro artigo sobre avaliação de um programa de treinamento em habilidades sociais, deram novo impulso ao desenvolvimento da área no Brasil que tem se expandido a cada ano. Um indicador desse crescimento pode ser aferido nos congressos, alguns já incluindo a temática das habilidades sociais como categoria de inscrição dos participantes (caso da ABPMC, por exemplo).

Ao longo desse tempo, não obstante diversos artigos isolados tenham sido publicados sobre o tema das habilidades sociais, foi em 2002 que se constituiu o grupo de trabalho da Associação Nacional de Pesquisa e Pós-Graduação em Psicologia, denominado "Relações Interpessoais e Competência Social", o que possibilitou reunir diversos pesquisadores da área e alavancar as pesquisas e publicações produzidas coletivamente. Por iniciativa deste grupo, dois livros foram publicados: um deles intitulado "Habilidades Sociais, Desenvolvimento e Aprendizagem" da Editora Alínea em 2003 e o outro "Estudos sobre Habilidades sociais e Relacionamento Interpessoal" pela Editora Casa do Psicólogo em 2004. Além disso, foram também realizadas duas edições do evento "Seminário Internacional de Habilidades Sociais" em 2007 e 2009. Sua terceira edição está prevista para agosto de 2011.

As habilidades sociais se caracterizam, segundo Del Prette e Del Prette (1999), por um rol de comportamentos sociais no repertório da pessoa, que contribuem para que esta lide de forma adequada com as ocasiões e oportunidades para relações interpessoais efetivas e satisfatórias, que caracterizam a competência social. Este conceito implica considerar a funcionalidade das habilidades sociais em termos das consequências que produz para 0 indivíduo, para seus interlocutores e grupo social. 
É no escopo das relações interpessoais que se inserem as habilidades sociais tendo sido evidenciado, reconhecidas vezes, que as interações sociais eficazes, ou seja, que atingem os objetivos pessoais e promovem melhor relacionamento com o outro são as que trazem maior satisfação pessoal e qualidade de vida (DEL PRETTE; DEL PRETTE, 1999). Os estudos sobre este tema buscam justamente prevenir dificuldades relacionais e superar problemas existentes. Assim, o campo das Habilidades Sociais se caracteriza não somente pela investigação e construção teórica, mas também pela perspectiva aplicada a diferentes campos de atuação como clínica, organizacional, educacional, dentre outras.

Este dossiê visa dar uma pequena visão ao leitor das contribuições atuais desse campo teórico-prático e está organizado de forma a refletir um pouco seu atual estado da arte. Dentre as preocupações associadas ao tema das habilidades sociais, estão estudos que envolvem caracterização do repertório de habilidades sociais de determinadas populações, desenvolvimento de métodos e instrumentos de pesquisa e aplicações do campo de habilidades a área do trabalho e educativa.

No primeiro artigo "A influência da idade e da escolaridade sobre a experiência empática de adultos" de Vanessa Dordron de Pinho, Conceição Santos Fernandes e Eliane Mary de Oliveira Falcone foram investigadas as relações entre a habilidade social empática, idade e escolaridade em 537 participantes. Foram encontrados como principais resultados que, quanto mais velhos os sujeitos, menor 0 altruísmo e maior a sensibilidade afetiva, e que, quanto maior a escolaridade, maior os escores relativos à flexibilidade interpessoal e altruísmo.

Nos artigos seguintes, são mostrados métodos e instrumentos para medida e promoção das habilidades sociais. Talita Pereira Dias, Paula Almeida de Oliveira, Maria Luiza Pontes de França Freitas, em "O método vivencial no campo das habilidades sociais: construção histórico-conceitual e sua aplicação" descrevem o processo de construção do método vivencial, elaborado originalmente por Del Prette e Del Prette, como enquadre básico para programas de habilidades sociais e o desenvolvimento desse método ao longo do tempo. Explicitam que o método vivencial está em contínua construção e observam que a sistematização, consolidação e desenvolvimento desse método são decorrentes de observações e análises de diferentes programas de treinamento em habilidades sociais. As autoras mostram ainda que estudos que adotam a utilização de vivências têm demonstrado a efetividade do método para promover habilidades sociais e diminuir seus déficits. Adriana Benevides Soares, Luciana Mourão e Thatiana Valory dos Santos Mello em "Estudo para a construção de um instrumento de comportamentos acadêmico-sociais para estudantes 
universitários" desenvolveram e validaram psicometricamente um instrumento de comportamentos encontrados no ambiente universitário composto de 34 itens e 6 fatores. Dado os índices de consistência interna, o instrumento pode ser recomendado para uso em pesquisa e aplicação.

Em "Habilidades sociais de desempregados de uma região de indústria coureiro-calçadista" Kamêni I ung Rolim, Karla Rafaela Haack, Jefferson Silva Krug, Camila Roberta Lahm e Alessandra Rodrigues Jacoby buscaram caracterizar as habilidades sociais de indivíduos em situação de desemprego. Os autores verificaram que estas pessoas apresentam níveis de habilidades sociais semelhantes ou superiores à média da população geral, ou seja, a dificuldade de empregabilidade e de manutenção do trabalho não se restringe a déficits em habilidades sociais, mas provavelmente inclui outros aspectos como, por exemplo, a incompatibilidade de características da população com as vagas oferecidas pelas empresas.

No contexto educativo, dois artigos abordam diferentes questões. Em "A relação das habilidades sociais educativas e das práticas educativas maternas com os problemas de comportamento em adolescentes" Gabriela Mello Sabbag e Alessandra Turini BolsoniSilva relatam um estudo que visa correlacionar as práticas educativas maternas, as habilidades sociais dos adolescentes e os problemas de comportamento em grupos de risco e de não risco para problemas de comportamento. Os resultados indicam que as práticas positivas maternas estão relacionadas à menor frequência de problemas de comportamento e à maior emissão de habilidades sociais em adolescentes. Fabio Biasotto Feitosa, Zilda A. P. Del Prette, Almir Del Prette, e Sonia Regina Loureiro em seu artigo “Explorando relações entre o comportamento social e o desempenho acadêmico em crianças" estudaram as correlações entre habilidades sociais, problemas de comportamento e desempenho acadêmico em 80 crianças de escolas públicas de segunda e terceira séries do ensino fundamental. Verificaram, levando em conta os relatos de pais e professores, que déficits em habilidades sociais podem ser mais comprometedores do desempenho acadêmico das crianças do que seus problemas de comportamento.

Por fim, é apresentada uma revisão bibliográfica temática, realizada por Valeria Morán, Nadia Soledad Prytz Nilsson, Ana Belén Suarez e Fabián Orlando Olaz, que descrevem os trabalhos realizados pelo Grupo de pesquisa do Laboratório de Comportamento Interperssoal em "Estado de la investigación en habilidades sociales en el laboratorio de comportamiento interpersonal (LACI) Cordoba - Argentina". Verificaram que a maior parte da produção científica em Habilidades Sociais tem como objeto os estudantes e profissionais da saúde e também envolve o desenvolvimento de instrumentos confiáveis e válidos para a avaliação de habilidades sociais. 
Também duas resenhas são apresentadas. Josiane Rosa Campos faz a resenha do Inventário de Habilidades Sociais para Adolescentes (IHSA-Del-Prette): manual de aplicação, apuração e interpretação descrevendo o instrumento e mostrando sua pertinência e atualidade. Na resenha do filme "Mary e Max: Uma amizade diferente" Lucas Cordeiro Freitas analisa a relação de amizade entre uma menina de oito anos que vive na Austrália e um homem de 44 que reside na América do Norte, ambos em isolamento. Mary apresenta problemas de comportamento do tipo internalizante e Max apresentava padrões comportamentais característicos da Síndrome de Asperger. A biografia dos personagens e suas relações ilustram comportamentos deficitários em habilidades sociais.

Para finalizar o dossiê, Carina Luiza Manolio (in memorian) e Bárbara Carvalho Ferreira entrevistaram Almir e Zilda Del Prette em "O campo das Habilidades Sociais no Brasil: Entrevista com Almir e Zilda Del Prette" apresentando como diversas questões sobre aspectos teóricos e práticos da atualidade são tratados no campo das Habilidades Sociais: o histórico da produção científica, preocupações sobre os primeiros estudos do campo, semelhanças e diferenças da produção científica no Brasil e em outros países, abordagens teóricas, métodos e técnicas de intervenção, os principais termos da área, equívocos e críticas mais frequentes.

\section{Referências Bibliográficas}

DEL PRETTE, Z. A. P.; DEL PRETTE, A. Psicologia das habilidades sociais: terapia e educação. Petrópolis: Editora Vozes, 1999.

\section{Endereço para correspondência}

Adriana Benevides Soares

Universidade do Estado do Rio de Janeiro - UERJ, Rua São Francisco Xavier, 524, Bloco F, $10^{\circ}$ andar, sala 10.005, Maracanã, CEP 20550-013, Rio de Janeiro-RJ, Brasil

Endereço eletrônico: adribenevides@gmail.com

\section{Notas}

* Professora Adjunta do Instituto de Psicologia da Universidade do Estado do Rio de J aneiro - UERJ, Rio de Janeiro, RJ, Brasil 